\title{
Erratum to: Thermodynamic Changes Induced by Intermolecular Interaction Between Ibuprofen and Chitosan: Effect on Crystal Habit, Solubility and In Vitro Release Kinetics of Ibuprofen
}

Amos Olusegun Abioye ' Rachel Armitage ' Adeola Tawakalitu Kola-Mustapha 1,2

Published online: 14 January 2016

(C) Springer Science+Business Media New York 2016

Erratum to: Pharm Res

DOI I0.1007/s I | 095-0I5-1793-0

There is an error in the 'Results and Discussion' section under

Thermo-analytical Characteristics.

Line 3: ... (melting peak at $80.07 \pm 1.76^{\circ} \mathrm{C} ; \Delta H=29.77$

$\pm 1.89 \mathrm{f} / \mathrm{g}) \ldots$ '. should read: ....melting peak at $80.07 \pm 1.76^{\circ} \mathrm{C}$;

$\Delta H=29.77 \pm 1.89 \mathrm{~kJ} / \mathrm{mol}(144.32 \mathrm{~J} / \mathrm{g})) \ldots$

Line 15: .. but slightly higher delta $\mathrm{H}(\Delta H=31.89 \pm 0.97 \mathrm{f} /$

g)...' should read: ...but slightly higher delta $\mathrm{H}(\Delta H=31.89$

$\pm 0.97 \mathrm{kf} / \mathrm{mol}(154.60 \mathrm{f} / \mathrm{g})) \ldots$

The online version of the original article can be found at http://dx.doi.org/I 0 . | 007/s | |095-0| 5- |793-0.

Amos Olusegun Abioye

aabioye@dmu.ac.uk

Leicester School of Pharmacy, De Montfort University, The Gateway,

Leicester LEI 9BH, UK

2 Department of Pharmaceutics and Industrial Pharmacy, Faculty of

Pharmaceutical Sciences, University of llorin, Ilorin, Nigeria 